\title{
A história da historiografia e o desafio dogiro linguístico
}

\author{
The History of Historiography and the Challenge of the Linguistic Turn
}

\author{
Rogério Forastieri da Silva \\ rforastieri@gmail.com \\ Professor \\ Colégio Etapa \\ Avenida Liberdade, 1046 \\ 01502-001 - São Paulo - SP \\ Brasil
}

\section{Resumo}

Esta exposição examina as relações entre a história da historiografia e o giro linguístico, este último tomado como um "desafio" à primeira. Inicialmente procura-se definir o que significa "o ponto de vista da história geral da historiografia", ou seja, tomar a história da historiografia em sua inteireza, dos gregos ao presente e, em consequência, colocar sob suspeição as proclamadas "rupturas", "cortes epistemológicos", "revoluções", "mutações" e "novas histórias" nos períodos recentes da história geral da historiografia; neste contexto, busca-se discutir o estatuto "científico" da história-discurso. Na segunda parte, caracterizamos o giro linguístico e a natureza do "desafio" que o mesmo vem a representar para a história da historiografia. $\mathrm{Na}$ terceira parte, situa-se o papel de Hayden White na formulação deste desafio e seus desdobramentos para a prática da história-discurso, ilustrando com exemplos de Hans Ulrich Gumbrecht e Peter Englund. A conclusão retoma argumentos de Siegfried Kracauer, Arnaldo Momigliano, Johan Huizinga, Carlo Ginzburg e Hayden White (este, em 2011) que, no conjunto, reforçam a importância de se considerar a história geral da historiografia como um todo (dos gregos ao presente) no tratamento da história-discurso; esta última, concebida como integrante de um "domínio intermediário" que, mesmo aspirando ao estatuto científico (compromisso com a verdade), não pode abandonar a construção da memória coletiva e o acerto de contas com o passado, daí decorrendo o caráter aproximativo do conhecimento histórico.

\section{Palavras-chave}

História da historiografia; Giro linguístico; Conhecimento histórico.

\begin{abstract}
This exposition examines the relationship between the history of historiography and the linguistic turn, the latter being considered a challenge to the former. At first we attempt to define the meaning of "the viewpoint of the general history of historiography" by taking the history of historiography in its entirety from the Greeks to the present, thereby undermining the credibility of self-proclaimed "ruptures", "epistemological cuts", "revolutions", "mutations" and "new histories" in the recent developments of the general history of historiography, and thus questioning the "scientific" status of historical discourse. In the second section we try to depict the linguistic turn and the nature of the "challenge" it poses to the history of historiography. In the third section, with examples from Hans Ulrich Gumbrecht and Peter Englund, we qualify the role of Hayden White in the formulation of this challenge and its consequences for the practice of the discourse history. The conclusion resumes the arguments of Siegfried Kracauer, Arnaldo Momigliano, Johan Huizinga, Carlo Ginzburg and Hayden White (his in 2011), which combine to reinforce the importance of considering the entirety of the general history of historiography when dealing with discourse history, conceived as part of an "intermediate domain" that aspires to a scientific status (the commitment with the truth), but which cannot break free from the construction of collective memory or the settling of accounts with the past, hence the approximate nature of historical knowledge.
\end{abstract}

\section{Keywords}

History of historiography; Linguistic turn, Historical knowledge.

Recebido em: 17/9/2013

Aprovado em: 1/7/2014 
O título desta exposição envolve dois objetos distintos, a "história da historiografia" e o "giro linguístico", e considera este último como um "desafio" ao primeiro. Esse "desafio", por sua vez, pode ser caracterizado como "provocação para um duelo", uma "incitação" a reagir. Supostamente existiria um objeto estabelecido - a história da historiografia, mais antigo, - cuja zona de conforto passou a ser questionada pelo referido "giro linguístico", mais recente. Tentemos, pois, caracterizar cada um desses objetos e, em seguida, procuremos especular sobre a natureza dessa provocação e suas possíveis respostas.

\section{O ponto de vista da história geral da historiografia}

Cabe, em primeiro lugar, um procedimento formal, a fim de que não pairem mal-entendidos sobre o objeto a que nos estamos referindo. Para tanto, é possível (e mesmo necessário) estabelecermos a seguinte nomenclatura:

-H1 - História-acontecimento, ou seja, todo o acontecer humano, em qualquer tempo, em qualquer espaço (caracterizado, portanto, pela infinitude de objetos);

- H2 - História-discurso, que é propriamente o trabalho do historiador, o relato fragmentário do acontecer humano; serve-se da narrativa com a finalidade de reconstruir este acontecer, para a constituição da memória social;

-H3 - Historiografia, ou seja, a história da história-discurso, as várias maneiras ao longo do tempo de se escrever este relato fragmentário, nas suas mais variadas modalidades;

- H4 - História das histórias da historiografia, ou seja, a historiografia das histórias da historiografia.

Portanto o foco de nossa exposição envolve as relações entre a história-discurso $(\mathrm{H} 2)$ e a história da história-discurso (H3), a que chamamos a história da historiografia.

Tomando-se como referência os modernos estudos historiográficos gerais, existe um relativo consenso entre autores consagrados (CROCE 1973; HAY 1977; KELLEY 1991) de que o primeiro empenho importante no sentido da realização de uma história geral da historiografia deveu-se ao historiador suíço Eduard Fueter (1876-1928) que, em 1911, publicou uma história da historiografia moderna abrangendo desde a época do Renascimento até o final do século XIX (FUETER 1914). A partir de então (isto é, a partir da Belle Époque), a produção historiográfica deixou de ser tratada apenas em bibliografias (LANGLOIS 1896), em histórias da literatura e de gêneros literários (ALBERT 1883; ROMERO 1888; LÉVRAULT 1905) para ocupar um lugar específico no interior da produção historiográfica propriamente dita.

A partir de um exame circunstanciado de histórias gerais da historiografia foi possível observar o que podemos chamar de uma mudança na estrutura e conteúdo delas, que deixaram ao longo do tempo de estar associadas e comprometidas com a formação de "historiografias nacionais" - a história como 
disciplina autônoma está diretamente associada ao processo de formação dos estados-nação a partir de finais do século XVIII (BERGER; DONOVAN; PASSMORE 1999), - tal como foi pioneira e compreensivelmente o modelo de história da historiografia adotado por Eduard Fueter, e estas passaram a conter uma ampla variedade de abordagens e temáticas (IGGERS 1975; BREISACH 1983; BOURDÉ; MARTIN 1983; KELLEY 2006; BURROW 2008).

Por esta via, com uma visão de conjunto da história da história-discurso desde os gregos à atualidade, demo-nos conta de que, no lugar de considerar apenas descontinuidades na escrita da história que, via de regra, são rotuladas de forma variada ("mutação" [CARBONELL 1976], "ruptura", "corte epistemológico", "revolução" [BURKE 1990]) na história da historiografia, foi possível refletir sobre esta insistência em ressaltar tais descontinuidades e avaliar com maior serenidade a natureza desta sucessão de "escolas históricas", "estilos históricos" ou, mais simplesmente, os modos variados de escrever a história-discurso.

O referido exame mostrou-nos a frequência com que cada nova tendência na forma de realizar a escrita da história define-se "nova", "moderna", "pósmoderna", ${ }^{1}$ o que, por sua vez, trata de se contrapor às formas anteriores, atribuindo a elas uma variedade de rótulos (história "descritiva", "factual", "positivista", "historisante" (FEBVRE 1992b, p. 114-118), "tradicional", "oficial", "ultrapassada", "datada"). Nos tempos atuais, parece que também entrou neste rol de designações a da história "marxista", bem como outras tantas possíveis (e futuras) denominações.

Como forma de legitimação, de definição de identidade, como esforço de superação, como uma outra maneira de escrever a história, o modo de escrever história que se propõe dominante em um determinado momento - por intermédio daquilo que às vezes é chamado de "escola histórica" - faz com que seus arautos tratem de caricaturar e desqualificar manifestações precedentes e se autoproclamem, por exemplo, representantes de uma "nova história". Esta denominação, a propósito, é muito antiga; é observável desde os séculos IV e $\mathrm{V}$ com Zósimo - Historia nea; e, ao longo do tempo, estendeu-se até a Nouvelle histoire nossa contemporânea (MONTELATICI 1916, p. 44; MOMIGLIANO 1987; NORWICH 1992; BROWN 1995). Na atualidade, além da utilização da expressão "nova", acrescentaram-se outras partículas, como é o caso, por exemplo, dos variados "pós" e "turns" na historiografia, como o presente linguistic turn.

Consideramos importante ressaltar que, no conjunto, as designações acima referidas, às quais se contrapõe a última novidade em matéria de historiografia, possuem pelo menos um elemento em comum: um propósito depreciativo que desqualifica de antemão a produção historiográfica precedente que tenha recebido algum desses rótulos. Esta maneira de estabelecer "relatos fundadores" de "novas histórias" possui um outro efeito perverso. As novas gerações de historiadores, a partir das referidas qualificações, deixam de examinar com o devido cuidado as produções anteriores e de situá-las no contexto histórico 
em que foram produzidas; enfim, deixam de dar-se conta da historicidade da própria escrita da história.

Veja-se, por exemplo, o zelo demonstrado por Lucien Febvre para especificar o que era historicamente próprio da "religião" de Rabelais (FEBVRE 1968), ou seja, que não bastavam documentos para identificar o personagem como ateu; portanto, recompondo a historicidade do contexto em que Rabelais vivia, contrasta significativamente com o tratamento a-histórico que dispensa a Charles-Victor Langlois e Charles Seignobos, os autores da Introduction aux études historiques (1898) (LANGLOIS; SEIGNOBOS 1992). Lucien Febvre ignora, em relação a eles, a razão pela qual davam tanta importância à questão da falsificação de documentos. No prefácio da reedição da referida Introduction, Madeleine Ribérioux destaca judiciosamente, entre outros aspectos, o quão pertinentes eram as discussões sobre aquela questão, pois, afinal, a obra e seus autores foram contemporâneos do Caso Dreyfus, no qual, como é sabido, cometeu-se, para além de outras atrocidades, um clamoroso erro judiciário e uma injustiça "legitimada" precisamente com a utilização de documentos forjados.

Assim, os historiadores antigos, "fora de moda", são, muitas vezes, citados; no entanto, não são objeto de um estudo mais detido - quem se daria ao trabalho, por exemplo, de ler Démocraties et capitalisme (1848-1860) em seguida aos ferozes ataques de Lucien Febvre? (POUTHAS 1948)² - pois já foram devidamente rotulados de "ultrapassados". ${ }^{3}$

Desta forma, o exame das referidas histórias gerais da historiografia 380 fortaleceu-nos a ideia de que, no trato da história da história-discurso, deve-se ter como importante referência o que chamamos "o ponto de vista da história geral da historiografia". Essa perspectiva considera que qualquer avaliação de cunho historiográfico deve levar em conta toda a história da historiografia, desde os gregos - portanto, desde Heródoto - até o presente (NOVAIS; SILVA 2011, p. 7-70; SILVA 2001).

É claro que, como já observamos, são perceptíveis, ao longo da história da história-discurso, mudanças de abordagens, temáticas e formas de exposição. Todavia, insistimos, não existem apenas rupturas, há também continuidades, nexos entre a mais atual produção historiográfica e as historiografias que Ihes antecederam. São, como observamos, recorrentes os modos de assinalar mudanças ao longo da história da história-discurso. Portanto, rupturas, continuidades e modos de anunciar rupturas pelos pioneiros de "novas histórias" são comuns ao longo de toda a história da historiografia.

Uma outra importante implicação a se considerar na avaliação de estudos de caráter historiográfico, do ponto de vista da história geral da historiografia, incide na própria concepção da história-discurso. Não se trata aqui, evidentemente, de reconstruir o processo de constituição desse setor do conhecimento como

\footnotetext{
${ }^{2}$ Sobre este autor e esta obra: FEBVRE 1992a, p. 99-103. O criticado autor integrou também uma prestigiosa coleção de história moderna: POUTHAS 1971, p. 389-415.

3 Há, evidentemente, uma importante exceção quando se trata de estudos historiográficos destinados especificamente a um determinado historiador como, por exemplo: ROMILLY 1998; MOMIGLIANO 1966; EYCK 1982; ROBERTS 1987; PORTER 1988; FINK 1991; CANNADINE 1992; MELLOR 1993; MÜLLER 2003; MILLER 2007; BENTLEY 2011; PAUL 2011.
} 
disciplina autônoma que adquire foros de "ciência" a partir do século XIX, mas de chamar a atenção para alguns aspectos que consideramos decisivos para o quadro de referências que estamos procurando especificar, qual seja, a questão de que o "giro linguístico" constitui um "desafio" para a "história da historiografia".

O impacto que as invenções, teorias, conquistas das ciências e consequentes tecnologias provocaram no século XIX em escala mundial talvez não tenha sido ainda extensiva e devidamente avaliado, mas, desde pronto, um aspecto pode e deve ser sublinhado: os rótulos "ciência" e seus derivados "científico" e "cientista", fizeram época e conferiram a seus portadores uma aura de credibilidade, reverência, respeitabilidade, autoridade e dignidade que tornava os objetos portadores de tais rótulos algo "acima de qualquer suspeita".

Desde então, a conquista de uma identidade, de uma legitimidade, enfim, o direito à própria existência de algum setor do conhecimento que se pretendia autônomo, passava ou se esforçava para definir-se "científico". A negação do caráter "científico" de algum pretendente ao rótulo veio a ser sinônimo de danação; ele se tornava um pária e não seria mais objeto de atenção, a não ser que fosse como exemplo de "escárnio e maldizer". Alguns pretendentes vieram a ter este desditoso destino, como, por exemplo, a "frenologia" de Franz Joseph Gall (1758-1828), a "eugenia", então denominada "ciência da boa criação" de Francis Galton (1822-1911) (BOGARDUS 1965, p. 347-357) e as teorias do chevalier de Lamarck (1744-1829) e de Cesare Lombroso (1836-1909), atualmente fora de qualquer consideração no campo da ciência.

Consideramos que é neste contexto histórico que devemos entender os esforços de Karl Marx e Friedrich Engels em postular um "socialismo científico" por oposição a um "socialismo utópico", bem como a insistência de Sigmund Freud em afirmar o caráter "científico" da psicanálise. Esta preocupação extrapolou mesmo os ramos propriamente do conhecimento e se desdobrou para outros setores, se lembrarmos que o formulador daquilo que é chamado de "espiritismo" definiu-o como "ciência da observação".

Assim sendo, não poderia ter sido diferente com a história que conquistava espaço, cátedras, recursos financeiros para a contratação de professores, para a realização de pesquisas e publicações, enfim, a disciplina adquiria direito de cidadania, "droit à la ville". Por esta via, podemos colecionar numerosas caracterizações da história como "ciência". São variados autores, com diferentes concepções que, não obstante, sustentam o caráter "científico" da história. Exemplos:

- "Conhecemos somente uma ciência, a ciência da história" (1845) - Karl Marx - Friedrich Engels (MARX 1965, p. 304)

- "A ciência da história é o resultado de percepções empíricas, de experiências e da pesquisa" (1858) - Johann Gustav Droysen (DROYSEN 2009, p. 36)

- "História é a ciência que investiga e expõe os fatos relativos [...] aos seres humanos [...]" (1859) - Ernst Bernheim (BERNHEIM 1937, p. 47) - "A história é e deve ser uma ciência" (1862) - Fustel de Coulanges (COULANGES 1973, p. 179.) 
- "... a presente Introdução aos estudos históricos é concebida como um ensaio sobre o método das ciências históricas" (1898) - Charles-VictorLanglois - Charles Seignobos (LANGLOIS; SEIGNOBOS 1992, p. 18)

- "Ainda não se tornou supérfluo insistir que a história é uma ciência, nada mais, nada menos." (1902) - John Bagnell Bury (BURY 1973, p. 210)

- "História é a ciência que trata de descrever, explicar e compreender os fenômenos da vida [...] dos homens" (1921) - Wilhelm Bauer (BAUER 1921. p. 38)

- "História, ciência do homem, ciência do passado humano" (1933) Lucien Febvre (FEBVRE 1992, p. 12)

• "... a história é uma ciência rigorosa ..." (1946) - Louis Halphen (HALPHEN 1948, p. 44)

A nosso ver, parece que os historiadores não levamos na devida consideração a historicidade desta conceituação da própria história então definida como ciência, como disciplina autônoma e acadêmica no contexto do boom científico do século XIX. Queremos deixar aqui registrada essa observação, que retomaremos adiante. Desta forma, ao tratar do impacto do "giro linguístico" sobre a história da historiografia, e aquele pensado como desafio, adotaremos o ponto de vista da história geral da historiografia, considerando portanto a história da história-discurso em toda a sua inteireza.

\section{2 o giro linguístico}

O chamado linguistic turn foi traduzido para o espanhol, e agora para o português, como "giro linguístico". Esta expressão ficou consagrada inicialmente no contexto da tradição da filosofia analítica anglo-saxônica para indicar que muitas das questões tidas como problemas na filosofia poderiam na verdade ser consideradas problemas de linguagem, ou seja, os filósofos poderiam estar fazendo mau uso da linguagem e, por essa razão, criando problemas que o uso adequado poderia demonstrar inexistentes (QUINE 2011, p. 11-35). ${ }^{4}$

Quanto à origem do uso dessa expressão, existe um consenso em afirmar que ela tenha sido utilizada pela primeira vez por Gustav Bergmann ${ }^{5}$ e que, por sua vez, inspirou o título da antologia organizada por Richard McKay Rorty, que reuniu artigos de autores consagrados na filosofia linguística com a finalidade de "mostrar os vários caminhos pelos quais os filósofos linguistas trataram a filosofia e o método filosófico nos últimos trinta anos" (RORTY 1992, p. I).

As reflexões de Richard M. Rorty associaram-se à história quando chamou a atenção de que, ao se utilizar a linguagem, nem sempre seremos capazes de saber distinguir com certeza se estamos respondendo a uma "compulsão da linguagem" ou a uma "compulsão da experiência". Em outras palavras, quando se estabelece uma interlocução há a tendência em confundir-se a "compulsão da experiência" - aquilo que se diz sobre o real, e a "compulsão da linguagem" - a

\footnotetext{
${ }^{4}$ Registro meu agradecimento por esta indicação bibliográfica ao professor João Carlos Passoni.

5 "All linguistic philosophers talk about the world by means of talking about a suitable language. This is the linguistic turn..." BERGMAN 1964, p. 177, apud RORTY 1992, p. 8.
} 
forma pela qual se diz algo sobre o real. Enfim, a questão levantada é se o objeto da interlocução são questões de linguagem ou questões de fato. Estabeleceu-se assim um interesse da filosofia da linguagem em relação à história, configurando o que veio a ser chamado de "filosofia da história linguística" (RORTY 1979, p. 169; apud ANKERSMIT 2004, p. 124-129). Por sua vez, os avanços e debates em torno do estruturalismo e da linguística vieram também resultar na insistência em afirmar o caráter não-referencial da linguagem, destacando-se, neste contexto, entre outros, Jacques Derrida e Roland Barthes.

Jacques Derrida chama a atenção para o fato de que a leitura não deve contentar-se em reduplicar o texto; entretanto, não pode também transgredir o texto em direção a algo que não é o próprio texto, especificamente, em relação a um referente que pode ser variado - tal como exemplifica: uma realidade metafísica, histórica, psicobiográfica, ou outra qualquer, ou, acrescenta, em direção a um significado fora do texto cujo conteúdo poderia dar-se, fora da língua (fora da escrita). Conclui, ao final desta digressão, que "nada há fora do texto" ("Il n'y a pas de hors-texte"), ou seja, a linguagem é autônoma, contém-se em si própria (DERRIDA 2004, p. 194-195).

Roland Barthes é ainda mais incisivo que Derrida. Debruça-se especificamente sobre o discurso histórico. Afirma que o fato só pode ser definido de maneira tautológica, o observado precede aquilo que é observável, entretanto o observável é somente aquilo que é digno de memória. Segundo Barthes, chega-se desta maneira ao que considera o paradoxo do discurso histórico, o fato tem somente uma existência linguística ("/e fait n'a jamais qu'une existence linguistique") - é o termo de um discurso - mas ao mesmo tempo, assinala, tudo se passa como se ele fosse uma "cópia" de uma outra existência, aquilo que chamamos de "real". Para Barthes, o discurso histórico é o único em que o referente é visado como exterior ao discurso, sem que, entretanto, seja possível atingi-lo fora do discurso (BARTHES 2012, p. 194).

Enfim, quanto ao seu conteúdo, para os propósitos que nos interessam, podemos afirmar que o giro linguístico veio a tornar-se um rótulo conveniente para evocar a afirmação de que a linguagem é autorreferente. Ou seja, no lugar da ideia de que a linguagem constitui-se basicamente como um meio para referir-se a objetos do mundo real (portanto como um elemento neutro para referir-se, nomear ou qualificar o real), ela possui sua especificidade e está longe de ser neutra.

Quando nos referimos ao giro linguístico no campo da história, já podemos afirmar que se estabeleceu um relativo consenso em associá-lo a Hayden White (PAUL 2011, p. 2; ANKERSMIT 2004, p. 119), e este consenso se deve ao fato de que, o que era até então uma discussão mais diretamente associada à filosofia da linguagem, de tradição anglo-saxônica (Richard M. Rorty), aos desenvolvimentos da linguística, e a pensadores franceses, especialmente os citados Jacques Derrida e Roland Barthes, agora passava também a dizer respeito à história. Hayden White, inspirado nesses autores bem como na teoria e crítica literária (especialmente na obra de Northrop Frye [FRYE 1973]), trouxe esta questão para o campo da história com uma obra sobre historiadores e 
filósofos da história do século XIX em sua obra Metahistória (WHITE 1992). A sua afirmação de que o texto histórico não passa de um "artefato literário" (WHITE 1994b, p. 97-116) a partir da perspectiva do giro linguístico veio, com razão, provocar variadas reações entre os historiadores, configurando a situação de "desafio" que, agora, passa a ser o objeto de nossa atenção.

\section{Respostas ao desafio}

Uma vez posta a questão do giro linguístico na historiografia, pode-se dizer que se estabeleceram intensos debates (e seria ocioso historiar aqui em detalhe cada um deles), especialmente aqueles que se mantiveram críticos em relação ao giro linguístico na historiografia. ${ }^{6}$ Outros autores, como Martin Jay, procuraram buscar um meio-termo em relação ao giro linguístico e a historiografia, alegando que não se poderia afirmar peremptoriamente que a linguagem fosse totalmente transparente ou totalmente opaca e que esta maneira de tratar a questão seria extremada (JAY 1982, p. 86-110). Por sua vez, há autores que afirmam que a prática da história não é mais a mesma, uma vez que devemos levar em consideração o giro linguístico (MUNSLOW 1993) e autores que procuraram tomar como referência o giro linguístico para além das fronteiras dos temas da história contemporânea (CLARK 2004).

Importa agora assinalar a forma pela qual o giro linguístico foi incorporado à história, não no plano teórico, mas na prática do historiador. Apesar de Herman Paul (que, infelizmente, não pôde comparecer a este seminário) afirmar que a influência de Hayden White na prática e escrita da história tem sido virtualmente "zero", esta afirmação contém um certo exagero (PAUL 2011, p. 1-14). Ao fim e ao cabo, entre várias, uma das mensagens que a obra de Hayden White deixa para os historiadores é: "narrem menos" ou "escrevam menos" e estarão fazendo uma "boa" história; ou, se "estiverem realmente com vontade de escrever, passem para a literatura". Por esta via podemos considerar como aqueles que assumiram as mensagens de Hayden White, e por esta razão exemplares, são os trabalhos de Hans Ulrich Gumbrecht e Peter Englund. A título de ilustração, tomamos uma obra de cada um destes autores.

Hans Ulrich Gumbrecht é o autor de Em 1926, vivendo no limite do tempo e pretende ser "não narrativo", ou seja, não se trata de um relato que nos transmita a história do ano de 1926 (GUMBRECHT 1999). Em capítulos curtos, sem ordem cronológica, mas alfabética, dividide-se em três partes: "Dispositivos", "Códigos" e "Códigos em colapso". A primeira parte corresponde a instantâneos sobre os assuntos correntes naquele ano, tais como "aviões", "boxe", "cremação", etc.; a segunda parte, pares de oposições, como por exemplo: "ação/impotência", "centro/periferia", "macho/fêmea", etc; a terceira parte, outros pares, cujas oposições agora são postas em dúvida: "imanência/ transcendência", "ação/impotência", "macho/fêmea", "presente/passado", etc. Na abertura do livro apresenta um "Manual do Usuário" que evoca Júlio

${ }^{6}$ Entre tantos: MOMIGLIANO 1993, p. 304; HANDLIN 1979; NOVICK 1996; NOIRIEL 1996; EVANS 1999; SPIEGEL 2009. 
Cortázar (Jogo da Amarelinha, 1963) e Milorad Pávitch (Dicionário Kazar, 1984), lembrando que o leitor pode iniciar a leitura em qualquer ponto, avançando ou recuando, embaralhando deliberadamente sincronia e diacronia; deixando-Ihe a tarefa de configurar o "seu" ano de 1926. Uma quarta parte - "Estruturas" discute o estudo e o ensino da história.

Peter Englund é o autor de The beauty and the sorrow: an intimate history of the First World War (ENGLUND 2012) e, como Gumbrecht, pretende ser "não narrativo"; a pretensão é mostrar como foi viver naquela época. No sumário, as partes: "To the reader", "Dramatis Personae", cinco capítulos correspondendo aos anos da guerra, um "The end" e um capítulo de fechamento com o título de "Envoi". Na abertura, o autor apresenta-se destacando suas duas profissões, quais sejam, historiador acadêmico e correspondente de guerra (Balcãs, Afeganistão, Iraque). Atenta para que, enquanto historiador, sonhara estar presente nos acontecimentos que descrevia; mas, quando teve esta oportunidade, deu-se conta de que não há qualquer garantia de entender o que está acontecendo. Portanto, seu livro é sobre a guerra, como foi sentida por alguns de seus contemporâneos, e não sobre o que ela foi. Para tanto, escolheu relatos de vinte personagens que viveram naquela época, de variadas origens e com diversos papéis; em comum, tinham apenas o fato de não pertencerem às altas hierarquias sociais. Na parte seguinte, indica nome, nacionalidade, ocupação e idade, variando da "esposa norte-americana de um aristocrata polonês" a uma "enfermeira inglesa no exército russo", passando por um "soldado venezuelano no exército turco", etc. Seguem-se os capítulos correspondentes aos anos de guerra antecedidos sempre de uma cronologia sobre os principais acontecimentos. Configura-se, assim, um misto de reprodução de textos dos personagens com as interpretações do autor. As duas últimas páginas - "Envoi" - reproduzem dois textos: um breve discurso de um sacerdote alemão e o depoimento de um soldado que, em 1925, face aos horrores da guerra, decidiu tornar-se um político. Este soldado chamava-se Adolf Hitler.

Não resta dúvida de que as obras de Gumbrecht e Englund são muito envolventes, prendem o leitor da primeira à última página e, desta forma, pode-se dizer que cumprem, pelo menos, uma parte do papel a que se destinaram, ou seja, conseguem recriar instantâneos do ambiente daqueles anos do início do século XX. O problema surge quanto a outras intenções daqueles autores: de, por assim dizer, "desaparecerem" da cena e deixarem os personagens "falar". Desde a escolha do título, do assunto, dos documentos e sua ordenação, dos comentários que fazem para o que está dito em cada documento, assinalam a forte presença de cada um deles; a narração está de certa forma subjacente, é como se deixassem ao leitor a tarefa de construí-la, - o que constitui uma meia verdade, na medida em que, sem os dados escolhidos, comentados e apresentados, tal "construção narrativa" por parte do leitor não seria possível. Queiram ou não, usando a cronologia ou não, existe um ordenamento, de tal forma que o leitor dispõe dos elementos para "compor a narrativa" do que lê a partir do "cardápio" oferecido pelos respectivos autores; não deixa, portanto, de ser uma obra autoral e, no limite, contém uma outra forma de apresentar a 
narrativa sem que, no entanto, ela deixe de existir. Assim, fundamentados nesses exemplos, não podemos concordar com a pretensão de ambos de construir algo "não narrativo" em história, e muito menos o que Englund chamou de "anti-história" (ENGLUND 2012, p. XIII ).

Ademais, atente-se que Derrida leva ao extremo as proposições do giro linguístico (Rorty), absolutizando a linguagem (nada há fora do discurso); homologamente, Gumbrecht leva ao limite a formulação de Hayden White (não há diferença entre os discursos histórico e ficcional), eliminando o discurso histórico (ao preconizar o silêncio do historiador) e restando apenas o documento. A nosso ver, este é o núcleo do problema, ou seja, a relação entre a historiografia e o giro linguístico.

\section{Chiaroscuro}

A esta altura vale comentar a postulação de Hayden White de afirmar que a história-discurso é um artefato literário. Em princípio, qualquer tipo de prosa não deixa de ser um artefato literário. Mas é claro que o autor, ao fazer esta afirmação, pretende ir mais além. Subjacentemente a esta qualificação, Hayden White está estabelecendo um par de oposições que ficam muito claras tanto em Metahistória quanto no artigo-manifesto "O fardo da história" (WHITE 1994a, p. 39-63); o par de oposições é precisamente: "história como ciência" (a que chama "de terceira categoria") e "artefato literário", ou seja, ou a história é ciência ou a história é literatura. Por sinal, não só Hayden White, mas todos os autores que postulam o caráter científico da história, têm como suposto esta lógica binária.

O mundo da ciência e da tecnologia existe e progride precisamente no interior dessa lógica. Ela é tão poderosa que envolve também o campo das humanidades e molda nossa maneira de ver o mundo: "positivo/negativo", "0/1", "ficção/não ficção", "natureza/cultura", "estado de natureza/sociedade civil", "cru/cozido", "evento/estrutura", e poderíamos multiplicar os exemplos. Contudo, no âmbito das humanidades, a história-discurso, diferentemente das demais "ciências" humanas, não pode conter-se nesta lógica binária, exatamente por ter um compromisso incontornável com a constituição da memória social.

Neste sentido, apesar da eficiência inquestionável da lógica binária, devemos entretanto ousar pensar sob certas circunstâncias para além dela, especialmente nos assuntos humanos, isto é, na história. Evocamos aqui o personagem de Shakespeare, Hamlet, que em seguida a ter visto o fantasma do pai, comenta com seu companheiro Horácio que há mais coisas entre o céu e a terra do que sonha a filosofia. Está aí contida uma sugestão que merece ser levada em consideração por, pelo menos, dois motivos. O primeiro é a sugestão de que os fantasmas existem, não nos moldes exatos da obra teatral mas em uma forma especial, toda a vez em que não "acertamos contas com o passado", tanto no plano da história de cada indivíduo como em um plano mais amplo. Neste último contexto, por exemplo, quando ficamos sabendo que é considerada crime na Turquia qualquer menção ao massacre de armênios; ou que a esmerada técnica de dissimulação das autoridades japonesas em afirmar uma "esfera de co-prosperidade da grande Ásia oriental " oculta as violências e massacres naquela região cometidos contra 
chineses e coreanos em um passado relativamente recente; ou o silêncio de um secretário-geral da ONU (Kurt Waldheim) e de seus cúmplices na Áustria, sobre seu envolvimento nada acidental com o nazismo; ou a moda de afirmar que o holocausto não passou de uma invenção; ${ }^{7}$ ou as dificuldades de se livrar de uma mentalidade senhorial-escravista nas ex-colônias do continente americano, onde formas variadas de trabalho compulsório eram (e continuam a ser) uma banalidade, - constatamos a "concretude" destes fantasmas. "Acertar contas com o passado" significa, entre outros aspectos, aprender a lidar e conviver com estes fantasmas que nos rodeiam. Certamente não será pela negação de sua existência - colocando-os sob o tapete ou punindo a quem ousar transgredir o silêncio - que os fantasmas desaparecerão. Para nós, a história é uma opção para o enfrentamento destas questões.

Outra sugestão, além da questão da existência dos fantasmas, é indagar-se sobre a possibilidade de existir uma alternativa à logica binária quando se trata de assuntos humanos, ou seja, pensar que possa existir algo além do "céu" e da "terra". Nem tudo é só branco ou só preto. Existem tonalidades, a imaginação humana, queiramos ou não, é capaz de propor alternativas à lógica binária quando, por exemplo, constatamos o chiaroscuro nas artes, o "purgatório" ("nem céu, nem inferno") em um setor do pensamento religioso; a propósito, o próprio pensamento religioso, seja ele qual for, é uma criação profundamente humana, constituindo uma das formas pelas quais os seres humanos procuram lidar com aquilo que os transcende e que não possuem meios de controlar ou explicar.

No interior desta moldura, sugerimos pensar em alguma alternativa à lógica binária no trato destas questões que envolvem a história-discurso. Sob essa perspectiva, podemos considerar um tanto deterministas as proposições de Hayden White, bem como, de maneira geral, a dos porta-vozes do giro linguístico. Os avanços da linguística e da filosofia da linguagem foram de tal monta que propiciaram afirmar, como vimos, a autonomia da linguagem como um universo específico, autorreferente e, neste contexto, o giro linguístico é um seu subproduto. Aliás, a própria expressão "turn" ("giro"), parece supor essa lógica. Um giro de cento e oitenta graus: ou temos um discurso "ciência", ou temos um discurso "ficção", no way out. Parte-se de um suposto que não está necessariamente explícito mas que é necessário aclarar.

Nesta altura, queremos evocar um artigo de Carlo Ginzburg - "Sinais: raízes de um paradigma indiciário" (GINZBURG 1989, p. 143-179) - no qual ele nos oferece uma sugestão que deve ser levada em consideração. Começa seu artigo fazendo menção a um crítico de arte que se faz passar por russo, mas que na verdade era italiano, que considerava os museus "depósitos de telas" e afirmava que era uma questão complicada a definição da autenticidade de uma obra de arte. Critica o que estava estabelecido nesta matéria, chamando a atenção para a falta de sentido de se tomar, por exemplo, um "sorriso" de Da Vinci para decidir sobre a autenticidade de uma tela a ele atribuída e que, pelo contrário, não

\footnotetext{
7 Para alguém como Arnaldo Momigliano, cujos pais foram remetidos e executados em um campo de extermínio nacional-socialista, é muito difícil aceitar a ideia de que não há objetividade disponível e que o texto histórico é uma forma de exercício de poder, um artefato literário e nada mais. Cf. STEINBERG 1991.
} 
seriam os sinais evidentes que possibilitariam distinguir o verdadeiro do falso, mas exatamente dos detalhes; lembrava, igualmente, que se deveria observar o desenho da orelha e das unhas (detalhes) e que, estes sim, seriam "índices" de autenticidade de uma obra. Ou seja, afirmava que era mais fácil copiar um "sorriso" de Da Vinci do que uma "orelha" ou um "dedo". O interessante nesta história é o depoimento de Freud, citado por Ginzburg, que declarou ter se inspirado no referido crítico para fundar a sua "ciência", a psicanálise. Ou seja, ao psicanalista não interessa o que vem à tona, o que é evidente, mas, precisamente, os 'fauxpas', os atos falhos, os detalhes. O conjunto desse arrazoado de Ginzburg vai mais longe, e ao encontro do que estamos comentando. No lugar de considerar como "epistemes", "rupturas" ou "mutações" a "escrita" e "antes da escrita", seu texto sugere que vejamos aí uma continuidade no que respeita à linguagem. Ou seja, desde os primórdios, a capacidade dos primeiros seres humanos em distinguir uma pegada ou um pelo de animal para identificá-lo, caçá-lo ou dele fugir, as pinturas rupestres - enfim, todos estes sinais -, tinham um sentido de dizer sobre algo que não estava mais lá, eram uma linguagem. Tais índices - sobre o que não estava mais lá - eram questão de vida ou morte de uma comunidade. Em outras palavras, não se pode negar à linguagem o seu caráter de índice, de referência. Veja-se, por exemplo, como Vladimir Arseniev mostra seu herói, o caçador Dersu Uzala: capaz de identificar animais, movimentos e situações a partir de sinais deixados no ambiente em que vivia, ele era apto a "ler" o idioma da natureza (ARSENIEV 1989). ${ }^{8}$

388 É evidente - e a linguística é clara a esse respeito - que é possível definir a autonomia de um sistema linguístico. A filosofia da linguagem mostra igualmente que não necessariamente a linguagem está associada a algum referente (como lembra muito bem Quine, no texto citado anteriormente): qual o "referente" da expressão "a redonda cúpula quadrada"? Todavia, desta constatação não se extrai, como se fosse um teorema, que a "linguagem seja autorreferente", que nada tenha a ver com o mundo extralinguístico (QUINE 2011).

Por esta via, retomamos nossa referência inicial sobre a insistência em definir a história como ciência, e como esta maneira de apresentar a questão supõe uma lógica binária "ciência/ficção". ${ }^{9}$ Discutindo precisamente sobre propostas de definição da história, Johan Huizinga toma as já referidas definições de Ernst Berheim e Wilhelm Bauer e mostra um problema: ao definirem a história como ciência, excluem, ipso facto, historiadores gregos, latinos, medievais e parte significativa da produção da historiografia moderna e contemporânea. Huizinga nos ensina que a história, de Heródoto aos dias atuais, corresponde à criação da memória, que tem algo a ver com a temporalidade e a definição de identidade, e que esse é um traço característico da parte do mundo em que vivemos, a chamada cultura ocidental. Por esta via, formula Huizinga uma definição, que

\footnotetext{
${ }^{8}$ Magnificamente iluminado no filme homônimo de Akira Kurozawa (1975).

9 Neste passo, não há como não observar que este par de oposições - "Isto é ficção", "Isto é literatura" - soa como algo equivalente a "isto não se deve levar a sério". A propósito, remetemos nosso leitor a uma bela e significativa defesa da literatura, realizada por Mario Vargas Llosa, publicada no jornal O Estado de São Paulo em 15.06.2003 e intitulada: Não é a literatura que envenena a vida.
} 
endossamos, segundo a qual a história "é a forma espiritual pela qual uma cultura acerta contas com o passado" (HUIZINGA 1980, p. 95).

Estas proposições de Huizinga não se perderam no tempo, mas continuam vivas, repercutindo sob variadas formas. Vale registrar neste mesmo sentido, a formulação de Siegfried Kracauer, que se serve de uma parábola para dizer que o discurso histórico se associa a uma busca de sentido; não se trata apenas de um registro, tal como fizeram no passado os analistas e os cronistas, mas uma busca de inteligibilidade que envolve a parte e o todo - evento, estrutura. Afirma estar interessado em saber algo sobre a constituição e o significado "deste ramo controvertido do saber". Pergunta-se se a história, pelo fato de ter-se emancipado da metafísica e da teologia, teria assim se tornado uma ciência. A história possui a pretensão de ser ciência e não é contestada. Não se pode mais dizer que ela seja uma arte, mesmo tendo características de um gênero literário, e também não é uma questão de opiniões impressionistas. A história, tal como a conhecemos hoje, situa-se em algum lugar entre as dimensões definidas por suas pesquisas e referências, em um campo intermediário. Entretanto, esse domínio intermediário não é reconhecido como tal. Afirma que existem modos de pensar tradicionais que nos cegam e impedem que reconheçamos este lugar. Estes modos de pensar tradicionais são a perspectiva científica e a obsessão filosófica, e ambas, à sua maneira, estão interessadas nas questões últimas do que é próprio da natureza e do que é próprio da condição humana. Sob tal moldura, falseiam-se os problemas associados à exploração histórica e para tentar enfrentá-los, Kracauer propõe-se a estabelecer o espaço deste "domínio intermediário" da história como algo que possui sua própria legitimidade, o que chama "um apanhado provisório sobre as penúltimas coisas", uma vez que as "últimas coisas" estão afetas à ciência e à teologia (KRACAUER 1995, p. 15-16). ${ }^{10}$

Para concluir, voltemos ao nosso personagem central, Hayden White, que associou o giro linguístico à história. Herman Paul, já citado, que escreveu um belo livro sobre Hayden White, fez questão de organizar a estrutura de sua obra de forma cronológica, temporal, e tem boas razões para assim proceder. Acompanha a biografia intelectual do autor, desde sua formação inicial como historiador, suas pesquisas em história da Igreja na Itália, suas primeiras obras propriamente históricas, entre as quais se destaca um balanço sobre a tradição cultural greco-romana (WHITE 1973), ${ }^{11}$ a publicação de seus ensaios associados ao giro linguístico, que Ihe renderam a atual notoriedade, até chegar ao professor Hayden White da época em que publica seu livro (2011). Assinala que Hayden White não perdeu sua postura combativa (que adequadamente chama de existencialismo humanista) mas, certamente, do ponto de vista de suas ideias, reformulou muito do que ficara fixado em Metahistória. É o que constatamos ao ler uma entrevista que concedeu a Erlend Rogne em Roma em 2007 (WHITE 2009, p. 63-75), ${ }^{12}$ na qual reafirma e revê algumas de suas posições.

\footnotetext{
${ }_{10}$ Registro meu agradecimento por esta indicação bibliográfica ao professor Guillermo Zermeño Padilla.

11 Por sinal, publicada no mesmo ano da Metahistória.

12 Em relação ao posicionamento político de Hayden White veja-se também: ADAMA 2001, p. 12-17.
} 
Hayden White lembra suas influências intelectuais e, o que é importante, discute as relações entre estrutura e evento, entre os limites impostos pelas estruturas e a indeterminação da condição humana, chamando a atenção para o fato de que temos de fazer escolhas a cada momento. Evoca o que reteve de sua leitura de Aristóteles sobre a impossibilidade de desempenhar de forma adequada todos os papéis que a sociedade nos atribui sem prejudicar os demais. Qualquer escolha será sempre em detrimento de outros papéis que temos de desempenhar. Assinala que vivemos em perene contradição, pois não podemos desempenhar, com a mesma competência, todos os papéis que somos obrigados a representar na sociedade; daí considerar que a busca por uma vida "consistente", "autêntica", é inautêntica.

No plano ético, define-se "situacionista" no sentido de que cada um de nós está em situações diferentes e não podemos ser a mesma pessoa em todo contexto. Quanto ao estruturalismo, afirma que extraiu dele o ponto de vista de que cada situação é sempre estruturada arbitrariamente, tal como a linguagem. O mesmo se dá em relação às regras que possibilitam a comunicação. Considera que o estruturalismo é importante; todavia, deixa pendente a questão da mudança de estruturas, que é a preocupação de pós-estruturalistas como Derrida, Foucault, Barthes e Lacan. De tal forma que estruturalismo e pós-estruturalismo se complementam.

Associa o estruturalismo à sociedade superestruturada da economia de mercado, que determina a natureza da escolha dos indivíduos, fazendo-os crer 390 que são livres. Com esta avaliação, acha que foi importante o existencialismo de Jean-Paul Sartre combinado com as concepções marxistas de história e sociedade. Lembra que Roland Barthes fez-lhe voltar a atenção para a teoria do discurso e da narrativa e, no interior desta, seu caráter tropológico. A narrativa é um modo de discurso que é pertinente a determinadas situações, mas não a outras. No decorrer da entrevista, agradece ao entrevistador por estabelecer uma data para um de seus escritos, pois afirma que escreve há cinquenta anos e que, ao longo desse intervalo, mudou de ideia várias vezes. Afirma sua predileção pela escrita modernista devido ao seu caráter experimental, questionando a estética do gosto. Para ele, o modernismo origina-se da constatação de que não vivemos em um mundo que tenha essência ou substância. A substância aristotélica morreu. Isto implica o fim da metafísica, o fim da religião. As coisas são aquilo que parecem ser, não há essências. Em resumo, a entrevista sugere uma retomada de posições de Hayden White, que considera como questão fundamental em história as relações evento/estrutura, determinismo/liberdade, e a importância das mediações face a tais problemas para além da postura "formalista"13 que adotou em sua Metahistória.

Neste percurso, queremos sugerir que não é uma reflexão desprovida de sentido ponderar sobre a lógica binária subjacente e que tem sido sustentada com tanta insistência para o enquadramento da história-discurso e aceitar o desafio de pensá-la como parte do referido "domínio intermediário" proposto

13 "Meu método é, para dizê-lo em uma só palavra, formalista" (WHITE 1992, p. 19). 
por Kracauer, que nos parece contemplar a história da historiografia em sua inteireza, desde os gregos até o presente, bem como os dois aspectos fundamentais, quais sejam, a construção da memória coletiva e o acerto de contas com o passado, faces da mesma moeda.

\section{Referências bibliográficas}

ADAMA, Frederick. Hayden White talks trash. Bad subjects, n. 55, p. 12-17, 2001. Disponível em: http://bad.eserver.org/issues/2001/55/white.html. Acesso em: 17 set. 2013.

ALBERT, Paul. Histoire de la littérature romaine. Paris: Charles Delagrave, 1883.

ANKERSMIT, Franklin R. Historia y tropología: ascenso y caída de la metáfora. Traducido por Ricardo Martín Rubio Ruiz. México: Fondo de Cultura Económica, 2004 [1994].

ARSENIEV, Vladimir. Dersu Uzala. Traduzido por Aguinaldo Anselmo Franco de Bastos e Lucy Ribeiro de Moura. São Paulo: Veredas, 1989 [1923].

BARTHES, Roland. O discurso da história. In: . O rumor da língua. Traduzido por Mário Laranjeira. São Paulo: WMF Martins Fontes, 2012 [1984].

BAUER, Wilhelm. Introducción al estudio de la historia. Traducido por Luis G. de Valdeavellano. Barcelona: Bosch, 1921.

BENTLEY, Michael. The life and thought of Herbert Butterfield: history, science and God. Cambridge: Cambridge University Press, 2011.

BERGER, Stefan; DONOVAN, Mark; PASSMORE, Kevin. Apologias for the nationstate in Western Europe since 1800. In: (orgs.).

Writing national histories: Western Europe since 1800. London: Routledge, 1999, p. 3-14.

BERGMAN, Gustav. Logic and reality. Madison, WI: Wisconsin University Press, 1964.

BERNHEIM, Ernst. Introducción al estudio de la historia. Traducido por Pascual Galindo Romeo. Barcelona: Labor, 1937.

BOGARDUS, Emory S. A evolução do pensamento social. Traduzido por Ruy Jungmann. Rio de Janeiro: Fundo de Cultura, 1965 [1960]. (2 v.)

BOURDÉ, Guy; MARTIN, Hervé. Les écoles historiques. Paris: Seuil, 1983.

BREISACH, Ernst. Historiography: ancient, medieval and modern. Chicago: University of Chicago Press, 1983.

BROWN, Peter. Authority and the sacred: aspects of the Christianisation of the Roman world. Cambridge: Cambridge University Press, 1995.

BURKE, Peter. The French Historical Revolution: the Annales School, 19291989. Cambridge: Polity, 1990. 
BURROW, John. A history of histories: epics, chronicles, romances and inquiries from Herodotus and Thucydides to the twentieth century. New York: Alfred A. Knopf, 2008.

BURY, John Bagnell. Inaugural lecture, Cambridge, 1902. In: STERN, Fritz (org.). Varieties of history: from Voltaire to the present. New York: Vintage, 1973.

CANNADINE, David. G. M. Trevelyan: a life in history. London: Fontana, 1992.

CARBONELL, Charles-Olivier. Histoire et historiens: une mutation idéologique des historiens français, 1865-1885. Paris: Privat, 1976.

CLARK, Elizabeth A. History, theory, text: historians ant the linguistic turn. Cambridge, MA: Harvard University Press, 2004.

COULANGES, Fustel de. Inaugural lecture, Estrasbourg, 1862. In: STERN, Fritz (org.). Varieties of history: from Voltaire to the present. New York: Vintage, 1973.

CROCE, Benedetto. Teoria e storia della storiografia. Bari: Gius. Laterza, 1973 [1913].

DERRIDA, Jacques. Gramatologia. Traduzido por Miriam Chnaiderman e Renato Janine Ribeiro. São Paulo: Perspectiva, 2004 [1967].

DROYSEN, Johann Gustav. Manual de teoria da história. Traduzido por Sara Baldus e Julio Bentivoglio. Petrópolis, RJ: Vozes, 2009.

ENGLUND, Peter. The beauty and the sorrow: an intimate history of the First World War. Translated by Peter Graves. New York: Vintage, 2012.

EVANS, Richard J. In defense of history. New York: W. W. Norton, 1999 [1997].

EYCK, Frank. G. P. Gooch: a study in history and politics. London: MacMillan, 1982.

FEBVRE, Lucien. De 1892 à 1933: examen de conscience d'une histoire et d'un historien. Leçon d'ouverture au Collège de France, 13.12.1933. In : Combats pour I'histoire. Paris: Albin Michel, 1992 [1953].

. Et I'homme dans tout cela? Sur un manuel. In: Combats pour I'histoire. Paris: Albin Michel, 1992a [1953].

. Sur une forme d'histoire que n'est pas la nôtre. L'histoire historisante. In: _. Combats pour I'histoire. Paris: Albin Michel, 1992b [1953].

. Le problème de l'incroyance au XVI'e siècle: la religion de Rabelais. Paris: Albin Michel, 1968 [1942].

FINK, Carole. Marc Bloch: a life in history. Cambridge: Cambridge University Press, 1991 [1989].

FRYE, Northrop. Anatomia da crítica. Traduzido por Péricles Eugênio da Silva Ramos. São Paulo: Cultrix, 1973 [1957]. 
FUETER, Eduard. Histoire de l'historiographie moderne. Traduit de l'allemand par Emile Jean Marie, avec notes et additions de I'auteur. Paris: Félix Alcan, 1914 [1911].

GINZBURG, Carlo. Sinais: raízes de um paradigma indiciário. In:

Mitos, emblemas e sinais: morfologia e história. Traduzido por Federico

Carotti. São Paulo: Companhia das Letras, 1989 [1986]. p. 143-179.

GUMBRECHT, Hans Ulrich. Em 1926: vivendo no limite do tempo. Traduzido por Luciano Trigo. Rio de Janeiro: Record, 1999 [1997].

HALPHEN, Louis. Introduction à I'histoire. Paris: Presses Universitaires de France, 1948 [1946].

HANDLIN, Oscar. Truth in history. Cambridge, MA: Harvard University Press, 1979.

HAY, Denys. Annalists ans historians: Western historiography from the Eighth to the Einghteenth centuries. London: Methuen, 1977.

HUIZINGA, Johan. En torno de la definición del concepto de historia. In:

El concepto de la historia y otros ensayos. Traducido por Wenceslao Roces. México: Fondo de Cultura Económica, 1980 [1946].

IGGERS, Georg G. New directions in European historiography. Hanover, $\mathrm{NH}$ : University Press of New England, 1975.

JAY, Martin. Should intellectual history take a linguistic turn? Reflections on the Habermas-Gadamer debate. In: LACAPRA, Dominick; KAPLAN, Steven L. (org.). Modern European intellectual history: reappraisals and new perspectives. Ithaca, NY: Cornell University Press, 1982, p. 86-110.

KELLEY, Donald R. Frontiers of history: historical inquiry in the $20^{\text {th }}$ century. New Haven: Yale University Press, 2006.

. Versions of history from Antiquity to the Enlighteenment. New Haven: Yale University Press, 1991.

KRACAUER, Siegfried. History: the last things before the last. Princeton: Markus Wiener Publishers, 1995 [1969].

LANGLOIS, Charles Victor; SEIGNOBOS, Charles. Introduction aux études historiques. Paris: Kimé, 1992. . Manuel de bibliographie historique. Paris: Hachette, 1896.

LEVRAULT, Léon. Les genres littéraires: I'histoire, evolution du genre. Paris: Paul Delaplane, 1905.

LYOTARD, Jean-François. La condition postmoderne. Paris: Minuit, 1979.

MARX, Karl; ENGELS, Friedrich. A ideologia em geral. In: CARDOSO, Fernando Henrique; IANNI, Octávio (org.). Homem e sociedade: leituras básicas de sociologia geral. Traduzido por Roberto Schwarz. São Paulo: Nacional, 1965. 
MELLOR, Ronald. Tacitus. New York: Routledge, 1993.

MILLER, Peter N. (org.). Momigliano and antiquarianism: foundations of the modern cultural sciences. Toronto: University of Toronto Press, 2007.

MILLS, Charles Wright. A imaginação sociológica. Traduzido por Waltensir Dutra. Rio de Janeiro: Zahar, 1965 [1959].

MOMIGLIANO, Arnaldo. El historicismo revisitado (1974). In: Ensayos de historiografía antigua y moderna. Traducido por Stella Mastrangelo. México: Fondo de Cultura Económica, 1993 [1977].

. On Pagans, Jews and Christians. Hanover, NH: Wesleyan University Press, 1987.

- The place of Herodotus in the history of historiography (1958). In: Studies in historiography. New York: Harper, 1966.

MONTELATICI, Giovanni. Storia della letteratura bizantina (324-1453). Milano: Ulrico Hoelpi, 1916.

MÜLLER, Bertrand. Lucien Febvre, lecteur et critique. Paris: Albin Michel, 2003.

MUNSLOW, Alun. Deconstructing history. London: Routledge, 1993.

NOIRIEL, Gérard. Sur la 'crise' de I'histoire. Paris: Belin, 1996.

394

NOVAIS, Fernando Antonio; SILVA, Rogerio Forastieri da. Introdução. In: ; __ (orgs.). Nova história em perspectiva. São Paulo: Cosac Naify, 2011. p. 7-70.

NOVICK, Peter. The 'objectivity question' and the American historical profession. New York: Cambridge University Press, 1996 [1988].

NORWICH, John Julius. Byzantium: the early centuries. New York: Alfred A. Knopf, 1992.

PAUL, Herman. Hayden White: the historical imagination. Cambridge: Polity, 2011. PORTER, Roy. Gibbon: making history. London: Phoenix, 1988.

POUTHAS, Charles. Peuples et Civilisations: Histoire Générale. Volume 16. Démocraties et capitalisme (18480-1860). Paris: Presses Universitaires de France, 1948 [1941].

. The revolutions of 1848. In: The New Cambridge Modern History. Volume 10. The zenith of European power, 1830-1870. Cambridge: Cambridge University Press, 1971 [1960]. p. 389-415.

QUINE, Willard Van Orman. Sobre o que há. In: De um ponto de vista lógico: nove ensaios lógico-filosóficos. Traduzido por Antonio Ianni Segatto. São Paulo: Editora da UNESP, 2011 [1948]. p. 11-35.

ROBERTS, David D. Benedetto Croce and the uses of historicism. Berkeley: University of California Press, 1987. 
ROMERO, Sílvio. História da literatura brasileira. Rio de Janeiro, 1888.

ROMILLY, Jacqueline. História e razão em Tucídides. Traduzido por Rosa Bueno. Brasília: Editora da Universidade de Brasília, 1998 [1956].

RORTY, Richard M. Introduction: metaphilosophical difficulties of linguistic philosophy. In: (org.). The linguistic turn: essays in philosophical method with two retrospective essays. Chicago: The University of Chicago Press, 1992 [1967].

Philosophy and the mirror of nature. Princeton: Princeton University Press, 1979.

SILVA, Rogerio Forastieri da. História da historiografia: capítulos para uma história das histórias da historiografia. Bauru, SP: EDUSC, 2001.

SPIEGEL, Gabrielle M. The task of the historian. Presidential Address. American Historical Review, fev. 2009. Disponível em: www.historians.org/info/ aha_history/spiegel.cfm. Acesso em: 17 set. 2013.

STEINBERG, Michael P. (org.). The presence of the historian: essays in memory of Arnaldo Momigliano. History and Theory: studies in the philosophy of history. Middletown, CT: Wesleyan University. Beiheft 30, v. 30, n. 4, p. 1-4, 1991.

WHITE, Hayden .The Greco-Roman tradition. New York: Harper \& Row, 1973.

Meta-história: a imaginação histórica do século XIX. Traduzido por José Laurênio de Melo. São Paulo: EDUSP, 1992 [1973].

. O fardo da história. In: . Trópicos do discurso: ensaios sobre a crítica da cultura. Traduzido por Alípio Correia de Franca Neto. São Paulo: EDUSP, 1994a [1966], p. 39-63.

. O texto histórico como artefato literário. In: Trópicos do discurso: ensaios sobre a crítica da cultura. Traduzido por Alípio Correia de Franca Neto. São Paulo: EDUSP, 1994b [1978], p. 97-116.

. The aim of interpretation is to create perplexity in the face of the real: Hayden White in conversation with Erlend Rogne. History and Theory: studies in the philosophy of history. Malden, MA: Wesleyan University, v. 48, n. 1, p. 63-75, 2009. 